\title{
CONCEITOS E MODELOS DE LETRAMENTO DIGITAL: O QUE ESCOLAS DE ENSINO FUNDAMENTAL ADOTAM?*
}

\author{
Regina Cláudia Pinheiro* \\ Universidade Estadual do Ceará \\ Centro de Educação, Ciências e Tecnologias da Região dos Inhamuns \\ Tauá, CE, Brasil
}

\begin{abstract}
Resumo: Este artigo, fundamentado em Street (1984; 2003), Scribner e Cole (1991), Kleiman (1995; 2014), Cavalcante Jr. (2003), Buzato (2003; 2007), Ribeiro (2006), Xavier (2011) e Borges (2017), objetiva descrever e analisar as práticas de letramento digital de alunos do Ensino Fundamental, desenvolvidas nas aulas de Português no laboratório de informática, a fim de identificar o modelo de letramento e a concepção de letramento digital subjacentes a essas práticas. Para tanto, realiza um estudo de caso, utilizando os seguintes instrumentos/técnicas para construção dos dados: (i) questionário aplicado aos profissionais do laboratório de informática; (ii) observação das aulas de Português realizadas no laboratório de informática; (iii) entrevista com os alunos. Os resultados indicam que as práticas de letramento digital exercidas pelos alunos nas escolas investigadas têm como base um conceito de letramento que considera a escrita como âncora dessas práticas e se apoiam no modelo autônomo de letramento.
\end{abstract}

Palavras-chave: Tecnologias digitais. Letramento digital. Modelos de letramento.

1 INTRODUÇÃO

O final do século XX e início do século XXI foram marcados por transformações que afetaram diversos setores sociais. Essas mudanças exigiram novos comportamentos dos cidadãos para inserir-se nessa nova sociedade. Dentre esses comportamentos, destaca-se o uso da língua nas mais diversas situações, o que requer uma mudança no ensino de Língua Portuguesa. Desse modo, a inserção das tecnologias digitais nas sociedades modernas demandou novas formas de pensar, ler, escrever e se comunicar (CHARTIER, 1999; LÉVY, 2003; ARAÚJO, 2007). Neste contexto, foram exigidas habilidades para o manuseio destas tecnologias e incorporados novos usos e práticas sociais de leitura e escrita às atividades diárias dos seres humanos. Além disto, o texto escrito não é a única forma de interação presencial ou a distância entre os indivíduos; ele está presente no universo das tecnologias aliado a outras formas de fazer sentido.

Considerando as questões mencionadas anteriormente, realizamos uma pesquisa cujo objetivo é analisar as práticas de letramento digital de alunos do Ensino Fundamental I de escolas públicas do município de Tauá - CE, desenvolvidas nas aulas de língua

\footnotetext{
* Este trabalho apresenta os resultados da pesquisa "PREDLED: Práticas escolares para o desenvolvimento do letramento digital", financiada pela FUNCAP (Fundação Cearense de Apoio ao Desenvolvimento Científico e Tecnológico), processo $\mathrm{n}^{\circ}$ BP2-0107-00080.01.00/15.

** Doutora em Linguística. Professora do Curso de Pedagogia do Centro de Educação, Ciências e Tecnologias da Região dos Inhamuns (CECITEC) em Tauá-CE. E-mail: regina.pinheiro@uece.br.
} 
portuguesa que ocorrem no laboratório de informática. Nossa análise busca verificar o modelo e a concepção de letramento digital que estão subjacentes às práticas exercidas pelos alunos. Para tal empreendimento, dividimos este arquivo em três seções, além desta introdução e das considerações finais. No primeiro item, discorremos sobre modelos de letramento e concepções de letramento digital. Em seguida, explicamos o estudo de caso que executamos para obtenção dos objetivos. Já na análise de dados, descrevemos e analisamos parte do questionário, das entrevistas e as observações realizadas na escola.

\section{LETRAMENTO DIGITAL: MODELOS DE LETRAMENTO E CONCEITOS}

As pesquisas sobre letramentos têm apresentado divergências relacionadas aos conceitos, considerando, principalmente, quais práticas de letramento podem enquadrarse nos modelos autônomo e/ou ideológico. Esses modelos se diferenciam, principalmente, porque o primeiro concebe a escrita como um ato individual, independente de suas condições sociais. Já para o modelo ideológico, ela é uma prática discursiva, cujos atores (autor/leitor) levam em consideração os elementos contextuais e culturais desse ato. Ressaltamos que essa dicotomia não deve ser compreendida como polos desvinculados, pois, para se fazer um uso social competente das formas de interação através da escrita, se faz necessário mobilizar habilidades individuais, tais como codificação e decodificação, estratégias de leitura, dentre outras. Sendo assim, ao praticar os diversos letramentos, os indivíduos perpassam, muitas vezes, por dimensões individuais para alcançar as práticas sociais.

No modelo autônomo, segundo Kleiman (1995), a escrita, por ser autônoma e concebida como uma aquisição individual, não depende das práticas discursivas nas quais está inserida; ela é "um produto completo em si mesmo, que não estaria preso ao contexto de sua produção para ser interpretado" (1995, p. 22). Neste modelo, a escola é a principal agência de letramento e a ênfase é atribuída somente à escrita, proporcionando poderes aos povos que a possuem. Nessa perspectiva, as suposições culturais e ideológicas são dissimuladas e apresentadas como neutras e universais e os efeitos do letramento são considerados benignos. Por isso, "as deficiências do sistema educacional na formação de sujeitos plenamente letrados [...] são decorrentes dos próprios pressupostos que subjazem ao modelo de letramento escolar." (KLEIMAN, 1995, p. 47). Deste modo, estudos (FERRARO, 1985, 1998) que se enquadram neste modelo concebem que há grupos nãoletrados, o que aqui é sinônimo de não-escolarizado ou analfabeto. Esta concepção de letramento pressupõe que há apenas um tipo de letramento - o que se refere à escrita - e determina as práticas escolares, considerando

\footnotetext{
a aquisição da escrita como um processo neutro, que, independentemente de considerações contextuais e sociais, deve promover aquelas atividades necessárias para desenvolver no aluno, em última instância, como objetivo final do processo, a capacidade de interpretar e escrever textos abstratos, dos gêneros expositivo e argumentativo, dos quais os protótipos seria o texto tipo ensaio. (KLEIMAN, 1995, p. 44)
} 
Portanto, se o modelo autônomo é o vigente das práticas escolares, as desigualdades sociais são reproduzidas e estimuladas na maioria das instituições de ensino, principais agências de letramento. Outras pesquisas, no entanto, consideram o letramento um fenômeno plural e contextualizado, condenando a visão acima segundo a qual o letramento é "dado" de forma neutra e, portanto, seus efeitos sociais são experimentados mais tarde (STREET, 2003). Conforme Kleiman (1995), essa maneira de enquadrar o fenômeno, seguindo um modelo ideológico de letramento, confirma que "as práticas de letramento mudam segundo o contexto." (p. 39), e "são aspectos não apenas da cultura mas também das estruturas de poder numa sociedade. (p. 38). Deste modo, estas práticas, carregadas de pressuposições ideológicas e políticas, refletem, muitas vezes, os modos de vida das classes sociais, reproduzindo e sendo determinadas social e culturalmente pelas estruturas de poder existentes em cada contexto.

Nesta perspectiva, os significados que a escrita assume para um grupo social dependem dos contextos e instituições em que ela foi adquirida (KLEIMAN, 1995). As pesquisas que consideram este modelo possibilitaram, segundo Street (2003, p. 77), Novos Estudos sobre Letramento (NLS) ${ }^{1}$, representando uma nova tradição nessa área saindo do foco da aquisição de habilidades para o letramento como prática social, o que "implica o reconhecimento de múltiplos letramentos, variando de acordo com o tempo e o espaço, mas também contestando as relações de poder". Assim, as práticas de letramento produzem efeitos diversos em condições diferentes e estão enraizadas em concepções de conhecimento, identidade e existência.

Esses novos estudos, para Street, consideram o texto como marca de poder, aspecto importante no modelo ideológico, e as práticas de identidade como elementos imprescindíveis nas pesquisas. O mesmo autor, analisando algumas pesquisas sobre letramento, constatou que os NLS têm articulado outras teorias vigentes de estudos de linguagem, como a noção de discurso, de Foucault, além de considerar as pesquisas em Análise do Discurso, Psicologia, História Social etc. Apresentando um panorama teórico sobre letramento, o autor menciona um volume ${ }^{2}$ com uma série de estudos sobre letramentos em contextos educacionais que sugerem mudanças teóricas e práticas. Desse modo, para Street (2003, p. 84),

\begin{abstract}
através desses contextos educacionais, os autores [do volume citado] estão preocupados não somente em aplicar os princípios gerais dos NLS, mas em oferecer críticas práticas de suas aplicações que nos forçam a refinar o conceito original [de letramento]: o volume, portanto, pretende ser não uma aplicação estática da teoria para prática, mas um diálogo dinâmico entre ambas.
\end{abstract}

Seguindo esse modelo de letramento, Cavalcante Jr. (2003) afirma que, nas sociedades mais tecnologizadas, nas quais o nível educacional dos indivíduos não se apresenta tão baixo quanto no Brasil, as práticas de letramento escolar são concebidas

\footnotetext{
${ }^{1}$ A sigla NLS provém do termo em inglês New Literacy Studies.

${ }^{2}$ A obra citada pelo autor, cuja referência é STREET, B. (forthcoming) (Ed.) Literacy Across Educational Contexts. Philadelphia: Caslon Publishing, encontrava-se no prelo, no período da publicação do artigo de Street, em 2003.
} 
como um fenômeno mais amplo. Nesta perspectiva, o termo pode representar sentidos que se expressam através de sentimentos, ideias e pensamentos, utilizando conceitos visuais, auditivos, sinestésicos, olfativos, gustativos, táteis e intuitivos. Sendo assim, o conceito de letramento admite outras formas de linguagem, como as expressões artística, computacional, matemática, musical, corporal, dentre outras. Desse modo, Cavalcante Jr. (2003, p. 26) se propõe a redefinir e desenvolver estudos considerando a concepção ampliada e pluralizada de letramento com base nas pesquisas americanas e nos estudos de Paulo Freire. Para o primeiro autor, letramentos são concebidos como "um processo de leitura diária do mundo - o mundo interior e exterior de cada ser humano - e a composição desses mundos através do uso de múltiplas linguagens de (re)presentação de sentidos", tais como a sonora, a corporal, a literária, a espacial, a espiritual, a visual e a multiforme.

Considerando a concepção mencionada por Cavalcante Jr. e a imersão das tecnologias digitais em diversos setores das sociedades modernas, fazendo surgir novas práticas e, consequentemente, novos termos para designar essas práticas, percebemos que esses estudos se intensificaram, surgindo a expressão letramento digital. Esse termo, assim como o letramento, diverge em seu conceito, pois são várias as definições encontradas para designar o letramento digital. Acreditamos que isso ocorre porque as tecnologias digitais possibilitam uma gama variada e diversificada de práticas sociais e também porque surgem novas ferramentas e novas possibilidades muito rapidamente. Dentre essas definições, muitas delas têm como âncora a escrita, haja vista serem os atos de ler e escrever o cerne de muitos conceitos de letramento. Assim, alguns conceitos de letramento digital se configuram como as práticas sociais de leitura e escrita realizadas através das ferramentas digitais (SOARES, 2002; MARCUSCHI, 2004; RIBEIRO, 2007; VICENTE; CAMPOS, 2016). Essas definições deixam implícito que quem consegue digitar ou ler algo produzido em um processador de texto, como o word, é letrado digital, porém desconsideram outras práticas sociais realizadas através das tecnologias digitais que agregam, à escrita, outras modalidades, tais como a visual e a oral. Compreendemos que alguns desses autores construíram essas definições antes da Web 2.0 ou antes da sua popularização e que as práticas sociais naquela época, mediadas pelas tecnologias digitais, eram pautadas, principalmente, por textos escritos.

No entanto, se pensarmos nas práticas atuais mediadas pelas tecnologias, percebemos outras formas de fazer sentido tão (ou mais) presentes que a escrita. Citamos como exemplo o fato de que muitos adolescentes, quando desejam tirar dúvidas sobre um conteúdo da escola, vão ao Youtube assistir a videoaulas ${ }^{3}$. Dessa forma, o conceito de letramento digital na atualidade deve se pautar também por outros usos além da escrita, como expressa a definição de Buzato (2003, 2007), que o considera como práticas sociais que se entrelaçam e se modificam através das tecnologias de informação e comunicação, incluindo habilidades para construir sentidos a partir de textos multimodais e a capacidade para localizar, filtrar e avaliar criticamente a informação disponibilizada eletronicamente,

\footnotetext{
${ }^{3}$ Essas práticas são representações de aulas presenciais e se constituem através de textos, principalmente, orais. No entanto, em muitos casos, a modalidade visual é muito importante para a compreensão dos sentidos. Além do mais, consideramos que a escrita está subjacente a estas aulas, pois elas são, na maioria das vezes, explicações didáticas da produção do conhecimento, que é repassado através da escrita.
} 
além da familiaridade com as "normas" que regem a comunicação através do computador. Observamos, na definição proposta por Buzato, práticas mediadas por computador e outros dispositivos eletrônicos, como, por exemplo, uma apresentação em PowerPoint, uma brincadeira com jogos de videogame, dentre outros. Verificamos, no entanto, que, ao mencionar textos multissemióticos, o autor prioriza somente a característica da coocorrência de semioses no hipertexto e desconsidera outras, tais como interatividade, multilinearidade etc. No entanto, esta definição está mais apropriada do que as anteriores porque considera outras formas de linguagem além da escrita.

Reflexões como as apresentadas anteriormente sugerem que os letramentos no mundo tecnológico se constituem de diversos textos: impressos, visuais, orais, entre outros, mediados pelas tecnologias. Com isso, não queremos afirmar que há, nessas interações, necessariamente, todas essas modalidades, mas uma mescla de algumas. Além do mais, percebemos, no letramento digital, uma mescla de outros letramentos, como o letramento visual e o letramento informacional ${ }^{4}$, que são praticados harmoniosamente para fazer sentido, através das tecnologias digitais, num entrelaçamento de práticas nas quais uma auxilia a outra para obtenção dos objetivos dos usuários. Nesse sentido, ressaltamos que a escola deve considerar os diversos letramentos em suas práticas, pois, conforme Pinheiro e Araújo (2016, p. 426),

somente um ensino pautado no desenvolvimento dos diversos letramentos e não somente no letramento tradicional, o que é comum na educação brasileira, pode permitir que a educação saia dos muros das instituições e perceba o processo ensino-aprendizagem como algo para a vida, o que é uma demanda do mundo globalizado.

Acreditamos que grande parte da população brasileira tem acesso a essa mescla de possibilidades de letramento em suas práticas cotidianas. No entanto, no Brasil, o acesso da população às tecnologias digitais é inversamente proporcional ao desenvolvimento educacional da população, haja vista estarmos no topo dos países que mais acessam a internet e na segunda posição do ranking de acesso às redes sociais, no ano de $2015^{5} \mathrm{e}$ sermos $59^{\circ}$ colocado em leitura na avaliação do PISA no mesmo ano ${ }^{6}$. Um dos motivos dessa disparidade talvez seja o fato de que nem todas as escolas compreenderam a importância de incluir as tecnologias digitais como ferramentas para o desenvolvimento da aprendizagem dos alunos. Algumas delas compreendem, mas utilizam essas tecnologias com práticas pouco produtivas. Esperamos que os estudos sobre letramentos influenciem as práticas pedagógicas e as políticas públicas educacionais e contribuam

\footnotetext{
${ }^{4}$ Segundo Dudziak (2003, p. 30), o letramento informacional é um tipo de letramento que consiste na competência em buscar e acessar informação para o aprendizado, considerando "valores ligados à dimensão social e situacional", como valores éticos e morais.

${ }^{5}$ Pesquisa realizada pela organização We Are Social e publicada pela Revista Exame. Disponível em: $<$ http://exame.abril.com.br/negocios/dino/pesquisa-coloca-brasil-no-topo-de-ranking-de-acessos-onlinemostra-jose-borghi-dino89089766131/>. Acessado em: 8 ago. 2017.

${ }^{6}$ O PISA (Program for International Student Assessment) é a mais importante avaliação mundial, realizada pela Organização para a Cooperação e Desenvolvimento Econômico (OCDE) e atestou, em 2015, o nível em leitura, matemática e ciências de alunos de 15 anos de 72 países. Disponível em: <http://www.cartaeducacao.com.br/reportagens/brasil-mantem-ultimas-colocacoes-no-pisa/>. Acessado em: 8 ago. 2017.
} 
para diminuir os baixos índices educacionais que o Brasil tem "conquistado" nas avaliações internacionais. Esses estudos têm se voltado, inclusive, para novas demandas de letramento existentes nas sociedades modernas, tais como aqueles no universo da tecnologia, como é o caso da Pesquisa sobre o uso das tecnologias da informação e da comunicação no Brasil: TIC domicílios e TIC empresas 2007 (BALBONI, 2008).

Outros países, como Estados Unidos e França, já realizam avaliações para medir o letramento digital dos alunos. No Estados Unidos, por exemplo, já está inserido o Sistema de Letramento Tecnológico dentro da Avaliação Nacional do Progresso Educacional (NAEP). Como forma de avaliar o letramento tecnológico, esta pesquisa considera três diferentes áreas, a saber: tecnologia e sociedade; projetos e sistemas; tecnologia da informação e comunicação. $\mathrm{Na}$ área de Tecnologia da informação e comunicação, que nos interessa mais de perto, incluem-se habilidades de criatividade e inovação, comunicação e colaboração, pesquisa e fluência na informação, pensamento crítico, resolução de problemas e tomada de decisões. Nessa área, os alunos são avaliados em cinco subáreas: construção e mudança de ideias e soluções; pesquisa de informação; investigação de problemas do mundo real e acadêmico; reconhecimento de ideias e informação; seleção e uso de ferramentas digitais (USA, 2009). Já o governo francês, conforme Borges (2017), elabora instrumentos de pesquisa para avaliar o domínio de habilidades digitais de crianças, jovens e adultos baseado em cinco áreas, a saber: domínio dos fundamentos da tecnologia de computador; adoção de uma atitude ética; produção, criação, modificação e operação de documentos usando um software de texto; uso de produtos multimídia para pesquisa e/ou documentação; comunicação por meio de correio eletrônico. Segundo a referida autora, esses testes, cujo documento é intitulado Brevet informatique et internet, são aplicados nas escolas de ensino fundamental, médio, nas escolas técnicas e nas faculdades francesas. Já no Brasil, as políticas públicas relacionadas às tecnologias estão voltadas para acesso às tecnologias e formação de professores, mas desconsideram a avaliação do desempenho dos estudantes com referência ao uso dessas ferramentas para a aprendizagem.

\section{METODOLOGIA}

Neste item do trabalho, explicitamos a caracterização da pesquisa, a delimitação do universo e os instrumentos e técnicas utilizados para construção e análise dos dados.

\subsection{TIPO DE PESQUISA}

Com o objetivo de identificar os modelos e as concepções de letramento digital subjacentes nas práticas escolares de alunos de escolas de Ensino Fundamental I, do município de Tauá - CE, optamos por proceder a uma abordagem quali-quantitativa de pesquisa na construção e na análise dos dados. Desse modo, executamos um trabalho de campo do tipo longitudinal, a fim de captar o ambiente e a situação investigada para que os fenômenos fossem mais bem compreendidos e analisados à luz do contexto circundante. Sendo assim, o trabalho de campo se configura como um estudo de caso, 
definido por Yin (2005, p. 32), como “[...] uma investigação empírica que investiga um fenômeno contemporâneo dentro de seu contexto da vida real, especialmente quando os limites entre o fenômeno não estão claramente definidos". No contexto da pesquisa qualitativa, consideramos que, para compreender nosso objeto de análise - os letramentos dos estudantes - através de descrição e observação, esta abordagem é a mais adequada. Com relação ao tratamento quantitativo, alguns dados, apesar de terem sidos verificados numericamente, foram analisados considerando suas particularidades individuais.

\subsection{SUJEITOS DA PESQUISA}

Os sujeitos ${ }^{7}$ que participaram da pesquisa foram divididos em dois grupos: o primeiro era composto por profissionais lotados no laboratório de informática das escolas municipais de Tauá-CE; já o segundo grupo era formado por alunos do Ensino Fundamental I das referidas instituições. As escolas com as quais trabalhamos são de administração municipal, localizadas na sede, e possuem laboratório de informática em pleno funcionamento com os alunos, perfazendo um total de cinco escolas.

Com relação ao primeiro grupo, sabemos que cada escola de Ensino Fundamental I (do $1^{\circ}$ ao $5^{\circ}$ ano) de Tauá - CE conta com um laboratório de informática e um professor lotado neste ambiente, executando atividades para auxiliar os alunos nas disciplinas do currículo. No entanto, abordamos aqui somente aspectos relacionados à disciplina Língua Portuguesa, haja vista esse ser o principal componente responsável pelo desenvolvimento dos letramentos dos alunos. A decisão de trabalhar com esse grupo deveu-se ao fato de que lhe cabe auxiliar os docentes de sala de aula, planejamento atividades para serem executadas no laboratório de informática, bem como seus componentes são os principais responsáveis pela ampliação do letramento digital dos alunos.

Os alunos do segundo grupo foram escolhidos pelos professores do $5^{\circ}$ ano, usando como critério a seleção de dois bons discentes, dois medianos e dois com mais dificuldades, considerando seus conhecimentos em Língua Portuguesa. Selecionamos discentes de $5^{\circ}$ ano porque estão concluindo o Ensino Fundamental I e, para esse grupo, as tecnologias digitais são bastante atrativas. Considerando que entrevistamos seis alunos em cada escola, temos um total de trinta estudantes que participaram diretamente da pesquisa.

\subsection{INSTRUMENTOS/TÉCNICAS PARA GERAÇÃO DE DADOS}

A necessidade de elaborar esses instrumentos deveu-se ao fato de estarmos cientes de que, em um estudo de caso, "o pesquisador recorre a uma variedade de dados, coletados em diferentes momentos, em situações variadas e com uma variedade de tipos de informantes" (LUDKE; ANDRÉ, 1986, p. 19) para dar fidedignidade à pesquisa. A seguir, detalharemos os instrumentos/técnicas utilizados para geração dos dados: questionário, observação in loco e entrevista semiestruturada.

\footnotetext{
${ }^{7}$ O projeto desta pesquisa, por lidar com seres humanos, foi submetido ao Comitê de Ética em Pesquisas com Seres Humanos, da Universidade Estadual do Ceará, através do número CAAE 47324715.8.0000.5534 e obteve aprovação do referido órgão pelo parecer 1.294.203.
} 


\subsubsection{QUESTIONÁRIO}

Tendo consciência de que as atividades de letramento digital realizadas no laboratório de informática são planejadas pelo professor lotado nesse ambiente, consideramos importante ouvir a voz desse profissional. Sendo assim, aplicamos um questionário cujo objetivo era verificar como a escola planeja e organiza as atividades do laboratório no âmbito da disciplina Língua Portuguesa, a fim de estimular, formar e instrumentalizar os discentes para o desenvolvimento de suas práticas de letramento digital. Além disso, este instrumento serviu para averiguar: como é realizada a formação (inicial e continuada) desses profissionais no que tange ao uso das tecnologias de informação e comunicação na sala de aula e o seu interesse sobre a possível integração dessas tecnologias para o desenvolvimento do letramento digital dos alunos; e quais as dificuldades encontradas para a promoção dessas atividades.

\subsubsection{OBSERVAÇÃO IN LOCO}

Uma vez que, nas pesquisas sobre letramentos, o processo é mais importante que o produto final, procuramos acompanhar as atividades executadas no laboratório de informática, através da observação não participante. Segundo Rodrigues (2006, p. 92), esta técnica consiste na "coleta de dados a partir da observação e do registro, de forma direta, do fenômeno ou fato estudado". Na pesquisa, registramos os acontecimentos em um caderno de anotações: todas as orientações do professor, as dúvidas que os alunos proferiram e demais fatos considerados importantes. Além do mais, utilizamos, em algumas escolas ${ }^{8}$, um software de captação da tela do computador, denominado Cantasia Studio, que permite filmar os movimentos realizados na máquina e gravar a voz do sujeito, através de um fone de ouvido com microfone.

Para realizar as observações, entrávamos em contato com o docente responsável pelo laboratório no início da semana, a fim de sabermos se teria aula de Português naquele período, pois ele planeja atividades de todas as disciplinas e as executa neste ambiente. Esse planejamento tem como objetivo auxiliar os professores de sala de aula com os conteúdos abordados, e todas as turmas da escola vão ao laboratório uma vez por semana, conforme calendário instituído no início do ano. Como as aulas de Português no laboratório eram esparsas, a pesquisa teve uma duração de mais de um semestre e realizamos, em cada escola, uma média de quatro observações, obtendo, ao final da investigação, um total de dezenove registros. Como o conhecimento se dá no processo, numa construção em que o fazer e o refazer são partes do todo, consideramos este momento importante para dar respostas e/ou suscitar indagações essenciais para a pesquisa, possibilitando, através dele, confrontar as práticas de letramentos que puderam ser flagradas nas atividades realizadas pelos participantes. Dessa forma, obtivemos subsídios para verificar quais atividades são realizadas no laboratório de informática e quais modelos e conceitos de letramento digital conduziam essas práticas.

\footnotetext{
8 Não foi possível instalar o software Camtasia Studio em todas as escolas devido ao fato de os computadores de alguns laboratórios não suportarem a ferramenta.
} 


\subsubsection{ENTREVISTA SEMIESTRUTURADA}

A entrevista semiestruturada consiste num diálogo entre pesquisador e participante, no qual aquele estabelece um roteiro de perguntas a serem respondidas por este, mas deixa espaço para outros questionamentos que, porventura, surjam no decorrer do processo e possam ser explorados. O referido instrumento teve como objetivo captar as diferentes perspectivas dos discentes com relação às atividades de letramento digital realizadas pela escola e verificar quais práticas estes exercem fora da instituição escolar que se configuram como letramento digital, a fim de comparar e verificar se as atividades realizadas no laboratório são exercícios mecânicos (puramente escolares) ou uma simulação de práticas reais. A entrevista foi selecionada como instrumento de pesquisa porque ela pode nos fornecer "dados que não podem ser encontrados em registros e fontes documentais, podendo estes ser fornecidos por determinadas pessoas" (ROSA; ARNOLDI, 2006). Além do mais, alguns alunos poderiam ter dificuldades de leitura, o que comprometeria a veracidade dos resultados.

A entrevista foi realizada individualmente em uma sala disponibilizada pela escola. A gravação foi registrada através do programa Audacity, um software que grava e reproduz sons, utilizando um microfone acoplado ao computador. Após a realização, as entrevistas foram transcritas para posterior análise.

\section{ANÁLISE DOS DADOS}

A análise se inicia com um dos questionamentos da entrevista que intentava descobrir com quais objetivos os alunos acessavam a internet, a fim de visualizarmos as práticas de letramento digital em que estes investem fora da escola. Como resposta, descobrimos que mais de um terço (37\%) acessa a internet para jogar, 27\% o faz para realizar pesquisas de um modo geral, $22 \%$ para acessar redes sociais e $8 \%$ para baixar/ouvir/ver música e vídeo. Somente $2 \%$ não acessam a internet e $4 \%$ realizam outras atividades. Vejamos, no gráfico 1, os dados apresentados anteriormente:

\section{Gráfico 1 - Para que o aluno acessa a internet}

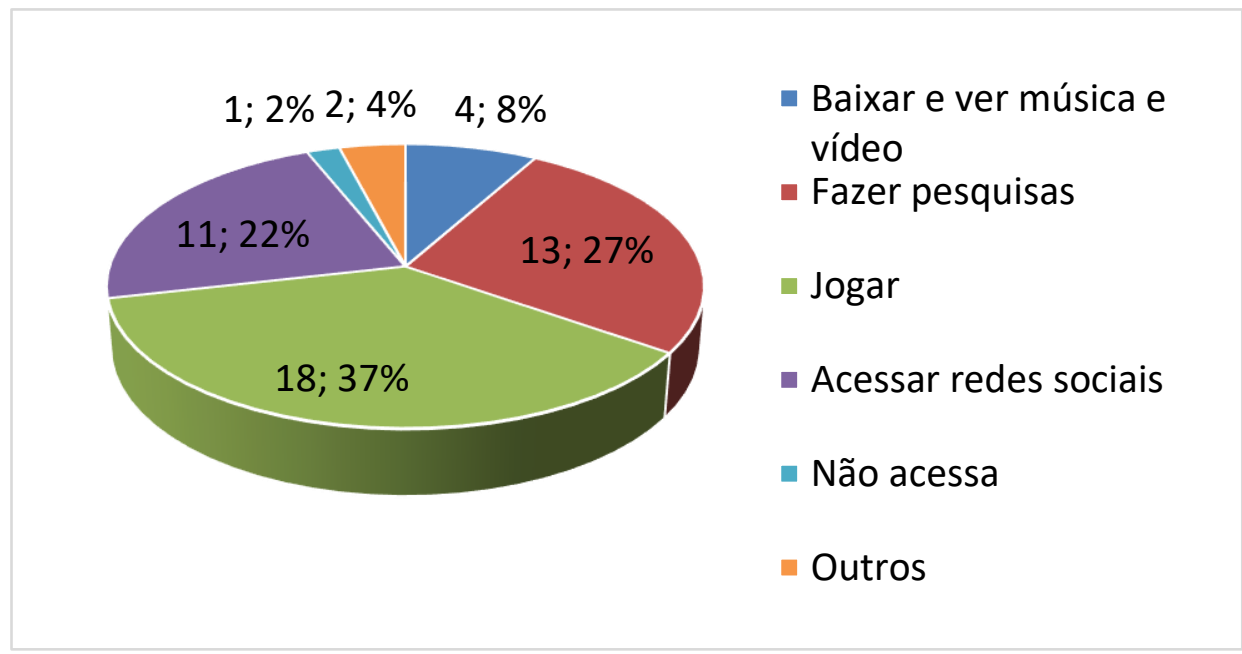


Os dados mostram que grande parte das práticas de letramento digital dos alunos fora da escola pode ser considerada de usos que mesclam várias modalidades, como oral, escrita, visual, não tendo primazia nenhuma delas. Além do mais, devemos destacar o uso maciço de jogos digitais, muito requisitados por crianças e adolescentes e sendo utilizados para entretenimento. Por serem práticas sociais com uso das tecnologias digitais, vemos a utilização desses jogos como práticas de letramento digital, em que a escrita não é a mais importante linguagem, pois encontramos indivíduos não alfabetizados cultivando essa prática. Consideramos, portanto, que as práticas de letramento digital dos alunos fora da escola não têm a escrita como âncora e compartilham do conceito de letramento digital, cujas interações mediadas pelas tecnologias demandam o uso de diferentes linguagens e exigem habilidades para acessar, filtrar e avaliar essas linguagens (BUZATO, 2003; 2007; BORGES, 2017; XAVIER, 2011).

Além de serem importantes para nós as atividades praticadas fora da escola, também nos interessam as práticas de letramento digital exercidas pelos alunos no laboratório de informática que lhes proporcionam prazer, por isso perguntamos de qual atividade realizada na escola eles mais gostaram. As respostas apresentadas condizem com as da questão anterior, pois confirmam a preferência pelos jogos digitais, mencionados por $57 \%$ dos entrevistados, seguidos por $21 \%$ que preferem atividades de Matemática e $11 \%$ que gostam de simulados ${ }^{9}$, conforme percebemos no gráfico 2.

\section{Gráfico 2 - Atividade realizada no laboratório de que o aluno mais gostou}

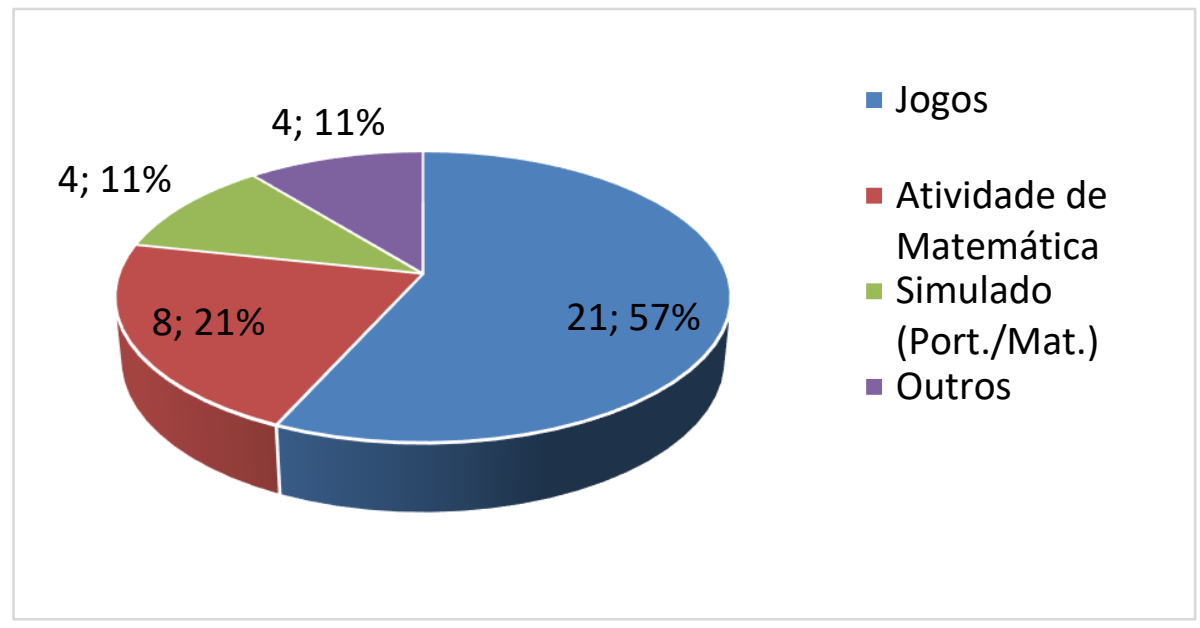

Os jogos digitais têm se tornado um passatempo para crianças e adolescentes; por isso as escolas, ao perceberem essa atração, procuraram trazer essa ferramenta para o processo de ensino-aprendizagem, a fim de tornar as aulas mais dinâmicas. Podemos considerar, portanto, que os jogos digitais abrem possibilidades pedagógicas para o ensino-aprendizagem. No entanto, conforme Ribeiro e Coscarelli (2009, p. 19), "não há

\footnotetext{
9 Os simulados, muito frequentes nas escolas participantes da pesquisa, são provas de Português e Matemática que os alunos vão responder no laboratório de informática, a fim de treinar para as avaliações externas (municipais, estaduais e federais).
} 
jogos disponíveis na internet que envolvam a alfabetização, o que encontramos são atividades didáticas [...] que sofreram simplesmente uma remediação para um novo suporte que possibilita o uso de recursos audiovisuais e de animação".

Observando as aulas que aconteciam no laboratório de informática, decidimos dividi-las por temáticas/estratégias, a fim de facilitar a análise. Sendo assim, das dezenove observações que realizamos, constatamos que mais da metade (58\%) intentava trabalhar leitura e interpretação de textos, $16 \%$ tinham algum conteúdo trabalhado através de jogos digitais, $11 \%$ eram atividades de produção textual, $10 \%$ trabalhavam o reconhecimento de pronomes e verbos e em $5 \%$ o docente apresentava o conteúdo através de slides e vídeos, conforme podemos observar no gráfico 3:

\section{Gráfico 3 - Atividades realizadas no laboratório de informática}

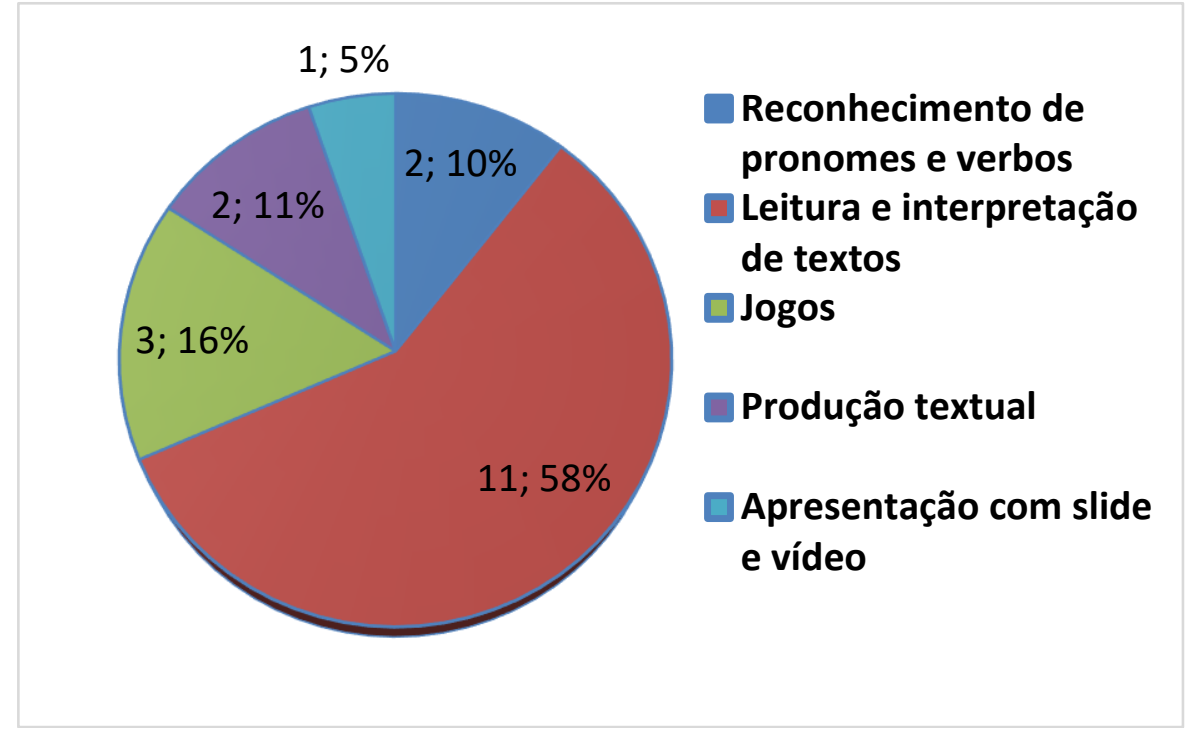

Se pensarmos no conceito de letramento como uma prática social, observamos um descompasso entre as atividades que os alunos realizam fora da escola e aquelas trabalhadas no laboratório, pois, enquanto os jogos digitais são preferência dos discentes fora da escola, dentro da instituição percebemos que somente $16 \%$ das aulas no laboratório são realizadas com essas ferramentas. Essa constatação reforça a afirmação de que as práticas de letramento na escola observada nem sempre são situadas (SCRIBNER; COLE, 1981; STREET, 1984, 2003), pois os professores da instituição quase sempre desconsideram a vida diária dos estudantes. Ressaltamos que os jogos digitais utilizados em instituições escolares são, geralmente, educativos, por isso, têm como objetivo a aprendizagem de algum conteúdo didático, sendo, na maioria das vezes, simulações de jogos que os alunos usam fora dessa instituição.

Com relação às atividades relacionadas ao reconhecimento de pronomes e verbos, cuja metodologia consistia em o aluno ler frases no computador e apontar os pronomes e verbos ou substituir, em frases soltas, os substantivos por pronomes pessoais, percebemos, nessa aula, a língua sendo ensinada de forma descontextualizada. No entanto, os docentes também trabalham atividades de produção textual com os alunos, o que pode ser considerado uma tentativa de ensino de língua como interação verbal. 
$\mathrm{Na}$ primeira atividade, observamos que, nessa tarefa, os discentes não foram devidamente orientados; por isso, a atividade se tornou difícil. As orientações dadas foram o tema e a sequência textual, sobre as quais o professor informou que a produção teria como tema o dia das crianças, podendo ser narração, descrição etc. Outra atividade de produção textual ${ }^{10}$, realizada em escola diferente, já contou com a apresentação de um texto pelo professor; no entanto, o texto foi utilizado para explicar que toda produção tem começo, meio e fim. Nesse dia foi solicitado, sem maiores detalhes, que os alunos escrevessem um texto com tema livre, e produzissem um desenho, ambos no programa Paint, o que mostra uma integração entre as linguagens verbal e não verbal. Portanto, pudemos verificar, nas duas observações relatadas anteriormente, que a produção textual é concebida nas escolas como um produto e que o texto é um instrumento de comunicação em que o foco está somente no autor, que detém as informações e as externaliza, desconsiderando o processo de interação verbal. Sendo assim, um ensino de produção textual que considere a língua como interação verbal deve trabalhar as etapas da escrita, incluindo planejamento, revisão etc. Além do mais, os alunos necessitam ter outras informações, tais como objetivo do texto, interlocutor, gênero discursivo etc. Essas observações demonstram que o modelo autônomo de letramento prevalece em atividades realizadas nos laboratórios de informática das escolas participantes da pesquisa, pois, segundo Terra (2013, p. 34), esse modelo aborda "o letramento como uma realização individual, ou seja, o foco concentra-se no indivíduo e não em um contexto social mais amplo no qual o indivíduo opera". Além do mais, verificamos que a concepção de letramento digital que subjaz a essas práticas considera, quase sempre, somente a linguagem verbal.

Já nas aulas que foram ministradas através de jogos digitais, pudemos verificar a utilização de várias modalidades, no entanto, em algumas delas, percebemos ainda a escrita descontextualizada. Na primeira aula, o docente utilizou dois jogos - Ditado $e$ Sopa de Letrinhas ${ }^{11}$. No primeiro jogo, o aluno precisava digitar as palavras que estão representadas através de imagens e sons, a fim de treinar a ortografia, conforme percebemos na figura 1. Com relação ao jogo Sopa de Letrinhas (Figura 2), o discente tinha de clicar nas letras dispostas na panela para escrever a palavra após ler uma dica, que aparece somente na forma escrita. Para ler essa informação, o aluno precisa já ter um certo conhecimento de leitura ou outra pessoa deve ler a dica para ele. Consideramos que essa pista poderia vir expressa na modalidade oral para estimular a autonomia dos alunos não leitores, visto que esta é considerada, segundo Burke (2015), um dos elementos da motivação, que deve estar presente em um jogo digital. Percebemos também que os dois jogos têm fases para o aluno se engajar e tentar passar de nível e, assim, ganhar recompensa, característica propícia para motivar os usuários dos jogos, que "giram em torno de motivar jogadores a atingirem objetivos que são compartilhados" (BURKE, 2015, p. 26). Com relação aos modelos e conceitos de letramento, percebemos novamente

\footnotetext{
${ }^{10}$ Nesse dia, o professor havia planejado uma atividade on-line, mas não conseguiu desenvolvê-la por falta de internet. A atividade de produção textual mencionada foi realizada por improviso. É importante ressaltar que os docentes comentaram que esse problema é recorrente em todas as escolas, o que dificulta a realização das atividades.

${ }^{11}$ Os jogos Ditado e Sopa de Letrinhas estão disponíveis em <http://www.escolagames.com.br/jogos.asp >. Acesso em ago. 2017.
} 
a adoção do modelo autônomo, no entanto, verificamos que as atividades desenvolvidas se apoiam em um conceito mais amplo de letramento, que considera outras linguagens, como podemos perceber no jogo Ditado (Figura 1).

\section{Figura 1 - Jogo Ditado}

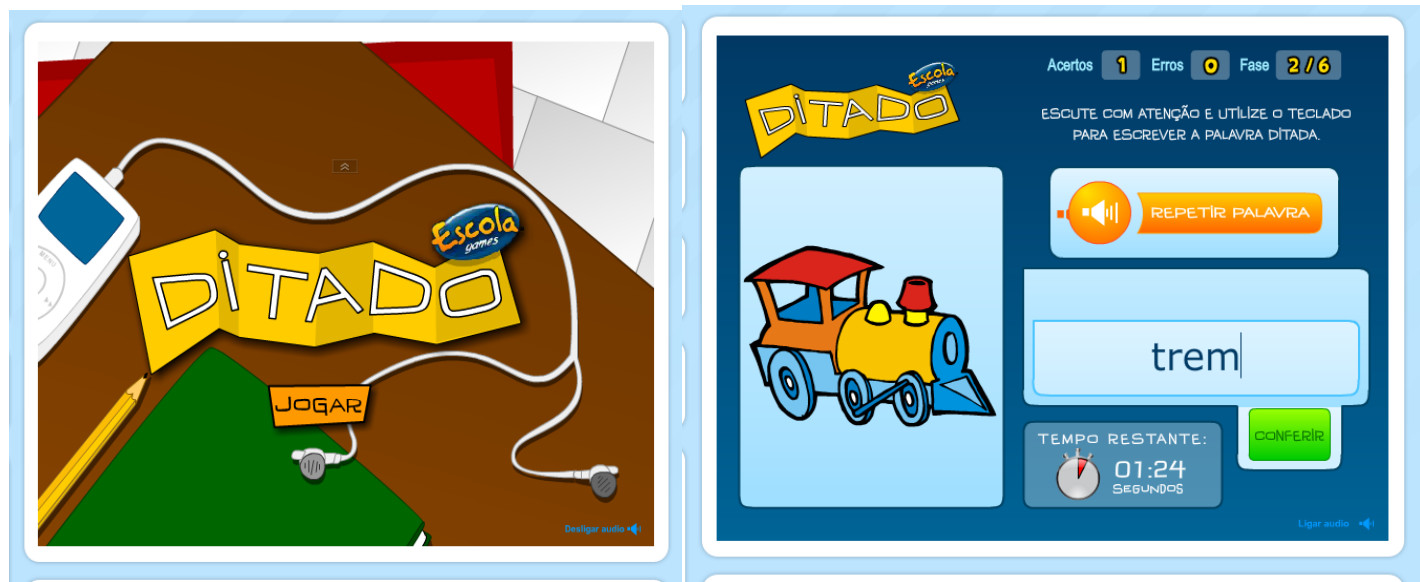

Figura 2 - Jogo Sopa de Letrinhas

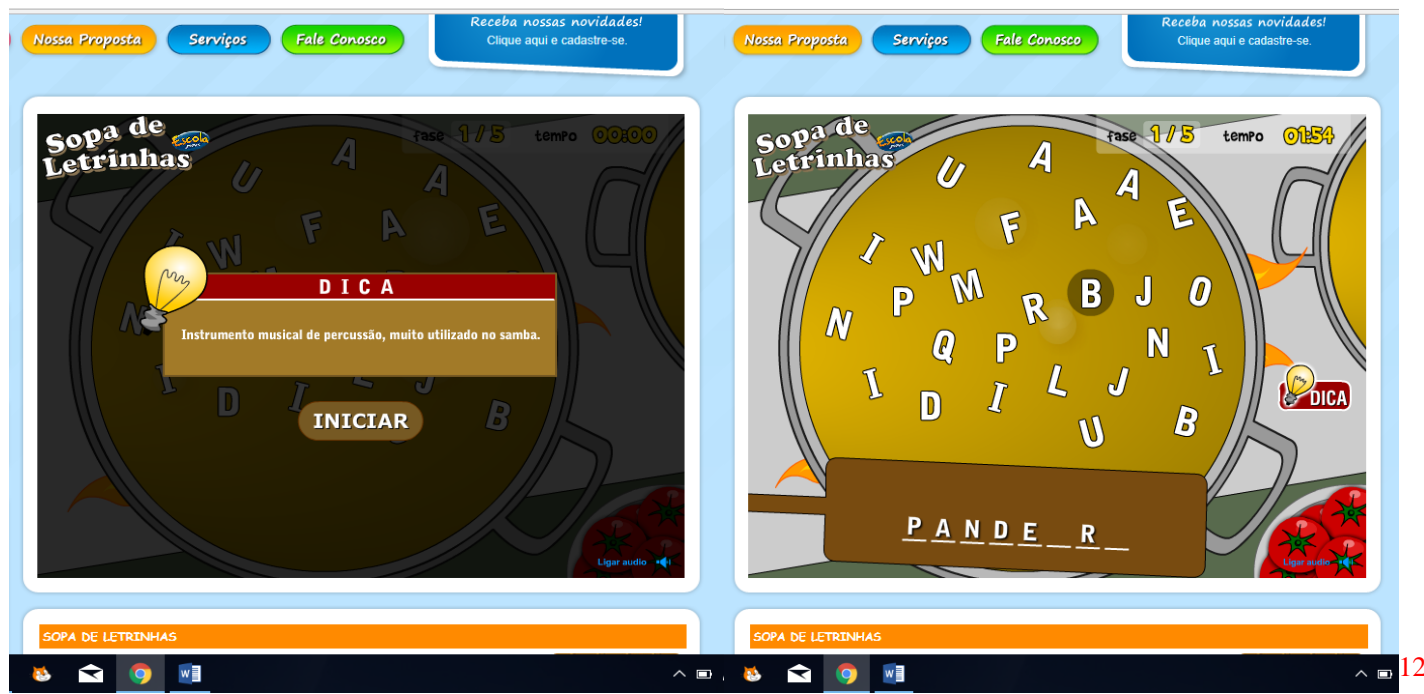

Verificamos, portanto, que as ferramentas digitais foram utilizadas, no ensino de gramática, de produção textual e ensino de leitura e escrita através de jogos digitais, para reproduzir atividades de uma língua descontextualizada. Considerando essa questão, Cavalcante Jr. (2003, p. 21) afirma que, no Brasil, estamos ainda, na maioria das escolas, reproduzindo o modelo autônomo de letramento, ao passo que, em outros países, como os Estados Unidos, muitos "pesquisadores vêm apresentando as suas insatisfações com o conceito reducionista de letramento que o restringe à aquisição de certas estratégias de comunicação, tais como a precisão de uso da palavra de forma descontextualizada, com grande ênfase na palavra escrita". Assim, mesmo quando os alunos usam ferramentas 
tecnológicas que abrem diversas possibilidades de práticas sociais, essas tecnologias são utilizadas para reproduzir velhas metodologias, conforme percebemos nas aulas observadas.

Em aula observada em outra escola, trabalhou-se o jogo Carta Enigmática ${ }^{13}$ (Figura 3), o qual consistia em decifrar várias mensagens. Nesse jogo, pudemos perceber uma mescla das modalidades oral e escrita e a presença de contextualização, uma vez que os alunos precisam decifrar códigos a fim de descobrir a mensagem enviada, na qual pudemos inferir elementos tais como interlocutores, objetivo do texto, gênero discursivo etc., se aproximando do modelo ideológico de letramento. Além do mais, o aluno tem o desafio de descobrir a mensagem secreta. Essa atividade, realizada em duplas, envolveu bastante os alunos, que estavam muito concentrados e comemoravam ao decifrar toda a mensagem. Observamos ainda que eles questionavam, refletiam e dialogavam uns com os outros para a resolução, comprovando a afirmação de Burke (2015) de que a motivação é uma das características dos jogos digitais e faz os jogadores se engajarem para alcançar seus objetivos.

Figura 3 - Jogo Carta Enigmática

\section{CARTA ENIGMÁTICA}

Dois amigos planejam um incrivel restaurante estranho! Quem decifrar os enigmas, pode ver o cardápio esquisito que eles criaram. Para vencer o desafio, é só clicar sobre os códigos e escrever as letras certas.

\section{JOGAR}

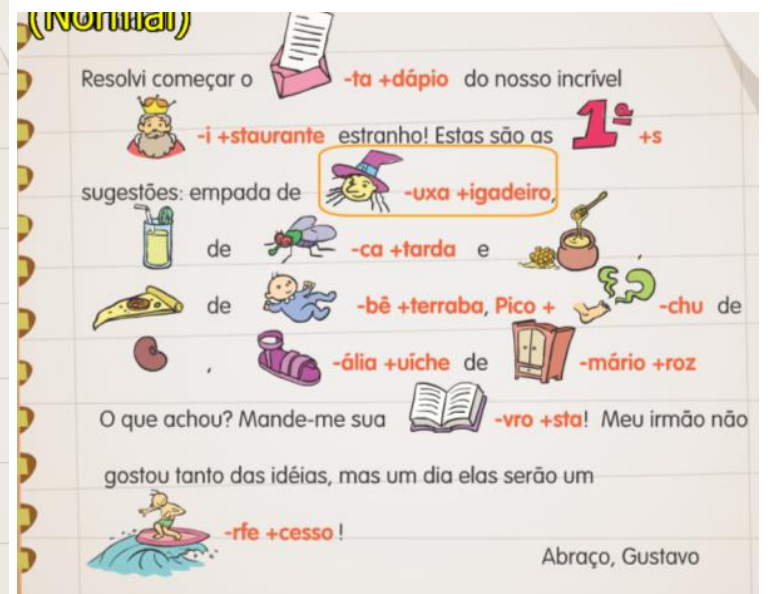

Além dos jogos, observamos também uma atividade que foi preparada com apresentação de slides e vídeos. Essa aula dizia respeito ao tema consciência negra e foi planejada para reforçar uma palestra a que os alunos haviam assistido sobre o assunto. $\mathrm{O}$ docente usou, para sua explicação, slides em PowerPoint e, após a explanação, exibiu um vídeo sobre igualdade. Após esses momentos, os alunos tinham de fazer um desenho que representasse o Dia da Consciência Negra, no programa Tux Paint, cujo uso foi explicado pelo professor. Percebemos, nessa atividade, uma mescla das modalidades oral, escrita e visual, o que caracteriza os textos da contemporaneidade e atrai bastante crianças e jovens, como pudemos observar nos discentes dessa sala, que demonstravam bastante interesse e interagiam com o professor. Verificamos, portanto, que a concepção de letramento digital adotada nessa atividade e naquela que trabalhou o jogo Carta

\footnotetext{
${ }^{13}$ O jogo Carta Enigmática está disponível em <http://www.atividadeseducativas.com.br>. Acesso em ago. 2017.
} 
Enigmática (Figura 3) considera as práticas sociais com uso das tecnologias digitais um processo que vai além da escrita, mesclando diversas linguagens para a construção de sentidos.

Observando as atividades de leitura e interpretação de textos no laboratório de informática, percebemos que, em sua grande maioria, elas foram realizadas a partir de textos escritos para o impresso e quase nenhuma delas possuía características hipertextuais, tais como links, articulação dos modos escrito, visual e oral etc., conforme podemos perceber no seguinte exemplo (Figura 4), capturado durante a observação das aulas, através do programa Cantasia Studio:

\section{Figura 4 - Texto utilizado para atividade de interpretação}

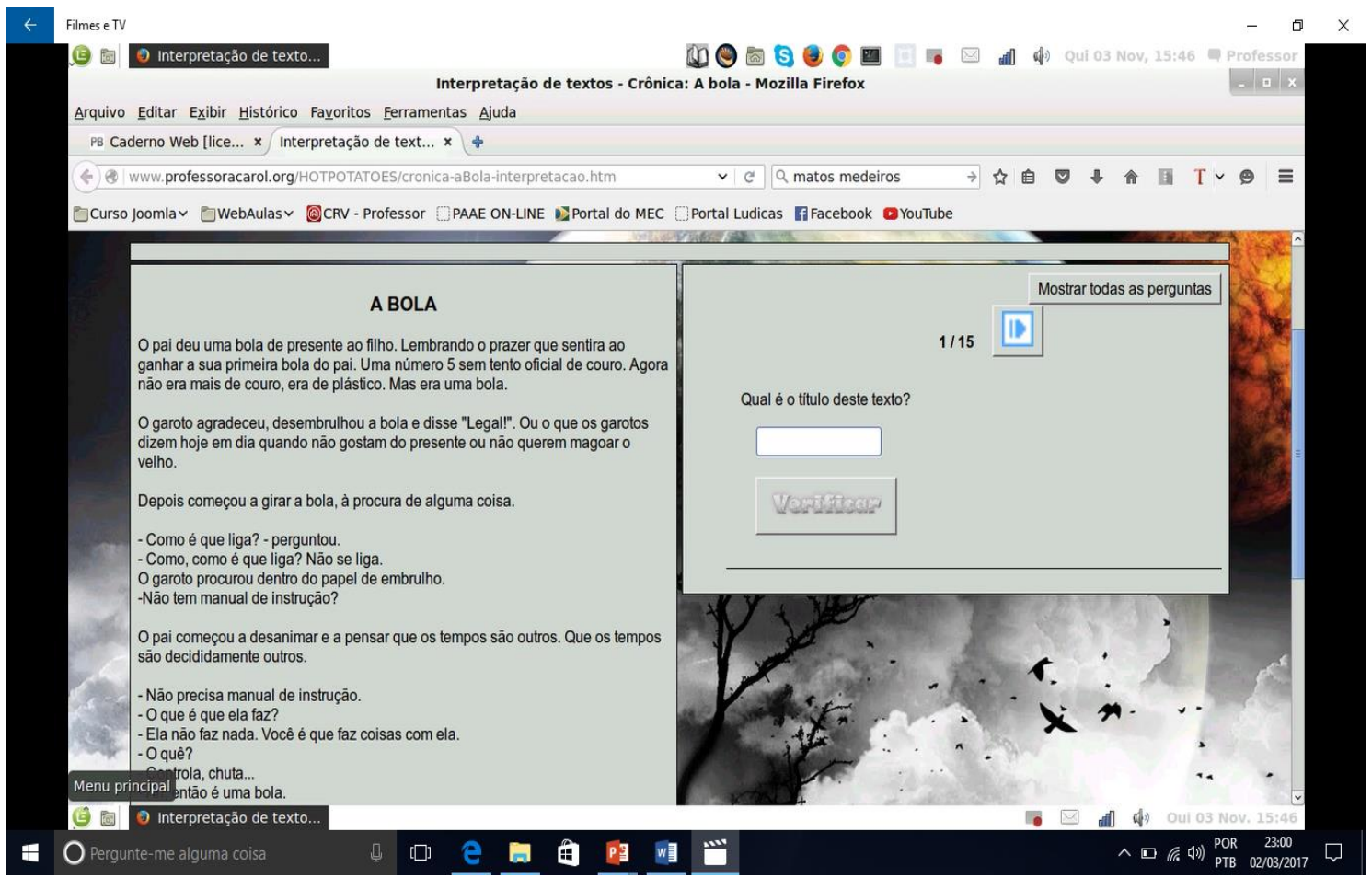

Essa atividade ${ }^{14}$ objetivava que os alunos lessem o texto e respondessem às questões relativas a ele, e consistia em localizar informações explícitas, tais como título e autor, identificar objetivo e tema do texto, fazer inferências etc. As observações realizadas comprovaram que os textos multimodais, tão presentes nas atividades cotidianas realizadas por meio da internet, nem sempre são trabalhados na escola, e que esta ainda considera o letramento como um fenômeno somente linguístico, desconsiderando seus aspectos políticos e sociais. Além do mais, percebemos que, quando o professor trabalha conteúdos de leitura e interpretação textual, seu planejamento está quase sempre voltado para uma concepção de letramento digital que tem como âncora a escrita, desconsiderando outras formas de fazer sentido com as ferramentas digitais, tais

14 A atividade foi retirada da internet e está disponível em <http://www.professoracarol.org/HOTPOTATOES/cronica-aBola-interpretacao.htm>. Acesso em ago. 2017. 
como textos orais, visuais etc. Desse modo, podemos inferir que, para o docente participante da pesquisa, desenvolver o letramento digital de seus alunos é ampliar e leitura e a escrita por meio das tecnologias digitais. Sobre essa questão, Kleiman (2014, p. 82) considera que

\begin{abstract}
os significados sociais de diferentes formas verbais e não verbais [...] e os modos em que são intencionalmente combinados para ressoar e construir outros significados [...] não são levados em conta na interpretação do texto multimodal e de seus variados suportes, apesar de a imagem estar ocupando, suplantando, até, a palavra escrita em muitas situações comunicativas de diversas instituições letradas.
\end{abstract}

Observamos também uma grande preocupação das escolas com as avaliações externas, que ainda não consideram o letramento digital de seus alunos, apesar de já encontrarmos pesquisas brasileiras que propõem uma matriz de letramento digital (DIAS; NOVAIS, 2009; ROSA, 2013; BORGES, 2017). Consideramos que, se houvesse no Brasil, como ocorre nos Estados Unidos e França (USA, 2009; BORGES, 2017), avaliações para averiguar o nível de letramento digital dos alunos, teríamos uma preocupação maior nas escolas em desenvolver outras questões relacionadas a esse aspecto, tais como domínio das tecnologias, integração entre as diversas modalidades para construção do sentido, acesso e avaliação das informações etc. Assim, talvez as escolas pudessem trabalhar com um conceito mais amplo de letramento digital e se desvencilhar das avaliações externas ${ }^{15}$, preparando mais seus alunos para a vida.

Pensamos que isso ocorre porque o docente, formado em uma cultura do texto escrito, não se sente capaz de ensinar e analisar esses textos, pois, conforme Kleiman (2014, p. 81), "ao observarmos os currículos oficiais para o ensino, em diversos estados e municípios do país, percebemos que novelas gráficas, livros ilustrados, jornais e revistas populares são tolerados, mas não aparecem como objetos de estudo e análise". Além do mais, os resultados mostrados anteriormente podem ter como causa a formação inicial e continuada do professor. Com relação à formação inicial, verificamos, através do questionário preparado para os docentes, que, dentre os cinco participantes, um é licenciado em Pedagogia, outro em Letras e três são licenciados em Química. Esses dados demonstram que o município de Tauá-CE tem uma política de contratação de professores adequada, pois está de acordo com a Lei de Diretrizes e Bases da Educação - LDB/96 (BRASIL, 1996), que exige nível superior para os docentes do Ensino Fundamental. No entanto, surpreende-nos que o professor licenciado em Química tenha de ministrar aulas de Português para alunos do Ensino Fundamental I, bem como o docente formado em Letras tenha de lecionar Matemática, pois estes profissionais elaboram atividades de todas as disciplinas. Com relação às disciplinas cursadas na faculdade que estão relacionadas ao uso das tecnologias, somente o pedagogo afirmou ter cursado uma disciplina relacionada às tecnologias de informação e comunicação; os demais participantes não tinham formação específica sobre o uso das tecnologias na educação.

\footnotetext{
${ }^{15}$ Durante nossas observações, várias vezes, os professores das escolas nos informavam que os alunos iriam para o laboratório de informática para fazer simulados das avaliações externas federais (SAEB) ou estaduais (SPAECE), nos quais eles iriam fazer provas de Português e Matemática. Nessas ocasiões, não fizemos observações porque este tipo de tarefa não interessa ao nosso projeto, pois essas atividades não tinham nenhuma diferença das provas impressas realizadas em sala de aula convencional.
} 
A formação continuada de docentes para o uso das tecnologias também indica uma das carências que pode justificar os problemas no planejamento das atividades para desenvolver o letramento digital dos alunos. Nesse quesito, somente um professor fez um curso de informática básico e outro estudou Excel básico. Com relação ao Linux, sistema operacional utilizado nas escolas, somente dois professores tiveram formação para este sistema. Em seguida, indagamos sobre a formação para uso das tecnologias na educação e, mais especificamente, no ensino de Português. Os resultados revelam que somente um professor fez curso específico; nenhuma formação foi voltada para o Ensino de Língua Portuguesa. No entanto, constatamos que os docentes têm reuniões semanais de planejamento e estudo com o responsável pelo Núcleo de Tecnologia Educacional da Secretaria de Educação Municipal, o que pode ser considerado uma formação em serviço. Verificamos, portanto, que o acesso às tecnologias digitais não é suficiente para ampliação do letramento digital dos alunos e que a formação dos docentes é um aspecto que não deve ser negligenciado pelas políticas públicas. Acreditamos ainda que essas formações poderiam, inclusive, ser realizadas com o uso das tecnologias, pois conforme Prado e Silva (2009, p. 70-71),

\footnotetext{
a formação do educador desenvolvida nos ambientes virtuais, que muitas vezes simula uma situação presencial desenvolvida numa perspectiva reflexiva que favorece a reconstrução da prática pedagógica voltada para integração das tecnologias e mídias aos conteúdos curriculares, caracteriza uma nova forma de aprender e de ensinar.
}

É importante ainda destacar que estas formações devem ter como cerne a ampliação do letramento digital dos alunos e não somente o uso das tecnologias digitais para a ampliação do letramento escolar, uma vez que, ao sair da escola, o discente, certamente, irá se deparar com questões que precisam ser resolvidas com o uso das tecnologias digitais.

\section{CONSIDERAÇÕES FINAIS}

As tecnologias de informação e comunicação são ferramentas importantes no ambiente escolar porque são atraentes para crianças e jovens e auxiliam no desenvolvimento e aprendizagem dos alunos, principalmente por oferecer diversificadas possibilidades de interação e construção de sentidos. Nesse sentido, as instituições de ensino devem utilizar essas ferramentas em suas atividades pedagógicas; no entanto, essas atividades não podem ser somente uma transferência do impresso para o virtual, pois é necessária a compreensão de que a inserção das tecnologias nas sociedades possibilitou mudanças nas formas de interagir e se informar.

Com a pesquisa, percebemos que algumas atividades realizadas no laboratório de informática são exercidas de forma descontextualizada e outras são atividades de interpretação textual, criação de texto etc. Verificamos também que os alunos se sentem atraídos por essas ferramentas e que os profissionais lotados nesse ambiente, apesar de perceberem as tecnologias digitais como um recurso para auxiliar a repassar os conteúdos, não têm formação adequada para compreender suas diversas possibilidades de uso para 
ampliar as práticas de letramento digital dos alunos. Sendo assim, reconhecemos que há alguns obstáculos a superar com relação ao uso das tecnologias digitais nas escolas públicas, a fim de se poder utilizá-las para alfabetizar letrando digitalmente os alunos.

Outro aspecto importante constatado na pesquisa é que, enquanto as tecnologias digitais proporcionaram o surgimento dos Novos Estudos sobre Letramentos, em que está subjacente o modelo ideológico de letramento, as escolas estão utilizando essas ferramentas para reforçar o modelo autônomo de letramento, ou seja, as tecnologias digitais são utilizadas para mascarar velhas metodologias. Além do mais, considerando a desproporcionalidade entre o acesso às tecnologias pelos brasileiros e o nível de letramento dessa mesma população, e verificando as descobertas da pesquisa, entendemos que seja necessário implantar políticas públicas tanto no que diz respeito à formação de professores quanto à instituição de avaliações que verifiquem o nível de letramento digital dos alunos, uma vez que é notório que o acesso às tecnologias digitais não é suficiente para o seu desenvolvimento.

\section{REFERÊNCIAS}

ARAÚJO, J. C. Internet e ensino: novos gêneros, outros desafios (Introdução). In: (Org.). Internet e ensino: novos gêneros, outros desafios. Rio de Janeiro: Lucerna, 2007. p. 15-17.

BALBONI, M. (Coord.). Pesquisa sobre o uso das Tecnologias da Informação e da Comunicação no Brasil 2007. São Paulo: Comitê Gestor da Internet no Brasil, 2008. Disponível em: <http://www.cetic.br/tic/2007/indicadores-cgibr-2007.pdf>. Acesso em: out. / 2008. BORGES, F. G. B. A construção de uma metodologia para o letramento digital. Raído, Dourados, v. 11, n. 25, p. 280-294, jan./jul. 2017.

BRASIL. Lei de Diretrizes e Bases da Educação Nacional. Lei número 9394, 20 de dezembro de 1996.

BURKE, B. Gamificar: como a gamificação motiva as pessoas a fazerem coisas extraordinárias. São Paulo: DVS Editora, 2015.

BUZATO, M. E. K. Letramento digital abre portas para o conhecimento. EducaRede. Entrevista por Olivia Rangel Joffily em 23/01/2003. Disponível em: <www.educarede.org.br>. Acesso em: 21 maio 2003.

Desafios empíricos-metodológicos para a pesquisa em letramentos digitais. Trabalhos em Lingüística Aplicada, Campinas, n. 1, p. 45-62, jan./jun. 2007.

CAVALCANTE Jr, F. S. Por uma escola do sujeito: o método (con)texto de letramentos múltiplos. 2. ed. Fortaleza: Edições Demócrito Rocha, 2003.

CHARTIER, R. A aventura do livro: do leitor ao navegador. Tradução de Reginaldo de Moraes. São Paulo: Editora UNESP/ Imprensa Oficial do Estado, 1999.

DIAS, M. C.; NOVAIS, A. E. Por uma matriz de letramento digital. In: III Encontro Nacional sobre Hipertexto. Anais...Belo Horizonte, CEFET-MG, 2009. Disponível em <http://www.hipertexto2009.com.br/anais/p-w/poruma-matriz.pdf>. Acesso em: ago. 2013.

DUDZIAK, E. A. Information literacy: princípios, filosofia e prática. Ciência da Informação, Brasília, v. 32, n.1, p. 23-35, 2003.

FERRARO (FERRARI), A. R. Analfabetismo no Brasil: tendência secular e avanços recentes. Resultados preliminares. Cadernos de Pesquisa, São Paulo, n. 52, p. 35-49, fev.1985.

Analfabetismo no Rio Grande do Sul: crianças e adolescentes, jovens e adultos. Cad. Educ, Pelotas, n. 10, p. 5-38, jan./jun. 1998.

KLEIMAN, A. B. Introdução: Modelos de letramento e as práticas de alfabetização na escola. In: (Org.). Os significados do letramento: uma nova perspectiva sobre a prática social da escrita. Campinas, SP: Mercado de Letras, 1995. p. 15-61.

Letramento na contemporaneidade. Bakhtiniana, São Paulo, v. 9, n. 2, p. 72-91, ago./dez. 2014. 
LÉVY, P. O que é o virtual?. Tradução de Paulo Neves. São Paulo: Ed. 34, 2003.

LUDKE, M; ANDRÉ, M. Pesquisa em educação: abordagens qualitativas. São Paulo: EPU: 1986.

MARCUSCHI, L. A. Gêneros textuais emergentes no contexto da tecnologia digital. In: MARCUSCHI, L. A; XAVIER, A. C. Hipertexto e gêneros digitais: novas formas de construção do sentido. Rio de Janeiro: Lucerna, 2004. p. 13-67.

PINHEIRO. R. C.; ARAÚJO, J. Letramento Hipertextual: um amálgama de letramentos demandados em cursos on-line. Trabalhos em Linguística Aplicada, Campinas, v. 55, n. 2, p. 401-430, 2016.

PRADO; M. E. B. B; SILVA, M. G. M. da. Formação de educadores em ambientes virtuais de aprendizagem. Em Aberto, Brasília, v. 22, n. 79, p. 61-74, jan. 2009.

RIBEIRO, A. E. Habilidades com a leitura e a escrita. Estado de Minas, Belo Horizonte: MG, 14 fev. 2006. Disponível em: <http://www.vivaleitura.com.br/artigos_show.asp?id_noticia=18>. Acesso em: jul. 2007.

RIBEIRO, A.L.; COSCARELLI, C.V. Jogos online para alfabetização: o que a Internet oferece hoje. In: ENCONTRO NACIONAL SOBRE HIPERTEXTO, 3., 2009, Belo Horizonte. Anais... Belo Horizonte/MG, 2009.

RODRIGUES, A. de J. Metodologia científica. São Paulo: Avercamp, 2006.

ROSA, F. R. Por um indicador de letramento digital: uma abordagem sobre competências e habilidades em TICs. CONGRESSO CONSAD DE GESTÃO PÚBLICA, 6., 2013, Brasília. Anais... Brasília/DF, 2013. Disponível em:

<http://www.escoladegoverno.pr.gov.br/arquivos/File/2013/V_CONSAD/VI_CONSAD/035.pdf>. Acesso em: ago. 2013.

ROSA, M. V. F. P. C.; ARNOLDI, M. A. G. C. A entrevista na pesquisa qualitativa: mecanismos para validação dos resultados. Belo Horizonte: Autêntica, 2006.

SCRIBNER, S.; COLE, M. The Psychology of Literacy. Harvard University Press, 1981.

SOARES, M. Novas práticas de leitura e escrita: Letramento na cibercultura. Educ. Soc., Campinas, v. 23, n. 81, p. 143-160, 2002.

STREET, B. Literacy in theory and practice. New York: Cambridge University Press, 1984.

What's "new" in New Literacy Studies? Critical approaches to literacy. In: Theory and practice.

Current Issues in Comparative Education, London, v. 5, n. 2, May 2003.

TERRA, M. R. Letramento e letramentos: uma perspectiva sócio-cultural dos usos da escrita. D.E.L.T.A., v. 29, n. 1, p. 29-58, 2013.

USA, Technological Literacy Framework for the 2012 National Assessment of Educational Progress. WestEd, 2009 (Discussion Draft - 7/24/09). Disponível em:

<http://www.docstoc.com/docs/11386736/Draft-Technological-Literacy-for-NAEP>. Acesso em: 6 mar. 2011.

VICENTE; R. B.; CAMPOS, J. M. T. Letramento digital nos anos iniciais do Ensino Fundamental. Revista Metalinguagens, n. 5, p. 78-89, maio 2016.

XAVIER, A. C. Letramento digital: impacto das tecnologias na aprendizagem da Geração Y. Calidoscópio, São Leopoldo, v. 9, n. 1, p. 3-14, jan./abr. 2011.

YIN, R. K. Estudo de caso: planejamento e métodos. Tradução de Daniel Grassi. 3. ed. Porto Alegre: Bookman, 2005.

Recebido em: 09/10/17. Aprovado em: 16/07/18.

Title: Concepts and models of digital literacy: what do elementary schools adopt?

Author: Regina Cláudia Pinheiro

Abstract: This article is based on Street (1984; 2003), Scribner and Cole (1991), Kleiman (1995; 2014), Cavalcante Jr. (2003), Buzato (2003; 2007), Ribeiro (2006), Xavier (2011) and Borges (2017). It aims to describe and analyze the digital literacy practices of students from elementary school. It is developed in Portuguese language classes which take place in a computer lab in order to identify the literacy model and digital literacy design that underlies those practices. To do so, we carried out a case study, using the following data construction tools/techniques: (i) questionnaire applied to professionals gathered in a computer lab; (ii) observation of Portuguese language classes held in a computer lab; (iii) 
interview with students. Most of the results show that digital literacy practices undertaken by students in the surveyed schools, have a concept of literacy, considering writing the anchor of these practices, based on an autonomous model of literacy.

Keywords: Digital technologies. Digital literacy. Models of literacy.

Titulo: Conceptos y modelos de letramiento digital: ¿lo que escuelas de enseñanza primaria adoptan?

Autora: Regina Cláudia Pinheiro

Resumen: Este artículo es basado en Street (1984; 2003), Scribner y Cole (1991), Kleiman (1995; 2014), Cavalcante Jr. (2003), Buzato (2003; 2007), Ribeiro (2006), Xavier (2011) y Borges (2017), u tiene el objetivo de describir y analizar las prácticas de letramiento digital de alumnos de la Enseñanza Primaria, desarrolladas en las clases de Portugués en el laboratorio de informática para de identificar el modelo de letramiento y la concepción de letramiento digital subyacentes a esas prácticas. Para ello, realiza un estudio de caso utilizando los siguientes instrumentos/técnicas para construcción dos dados: (i) cuestionario aplicado a los profesionales del laboratorio de informática; (ii) observación de las clases de portugués realizadas en el laboratorio de informática; (iii) entrevista con los alumnos. Los resultados indican que las prácticas de letramiento digital ejercidas por los alumnos en las escuelas investigadas tienen como base un concepto de letramiento que considera la escrita como áncora de esas prácticas, y se apoyan en el modelo autónomo de letramiento.

Palabras clave: Tecnologías digitales. Letramiento digital. Modelos de letramiento.

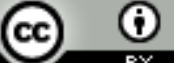

Este texto está licenciado com uma Licença Creative Commons Atribuição 4.0 Internacional. 